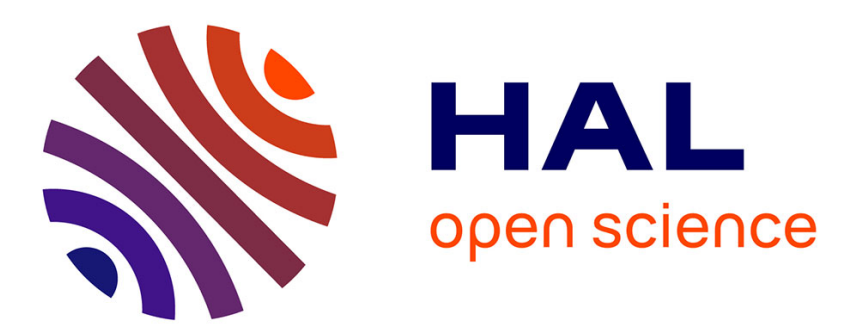

\title{
The torsion-tensile method for the characterization of cold metal formability
}

Jean François Fontaine

\section{To cite this version:}

Jean François Fontaine. The torsion-tensile method for the characterization of cold metal formability. 2nd International Conference on Material Processing Defects, Jul 1992, Bonn, Germany. pp.253-262, 10.1016/0924-0136(92)90182-R . hal-00803922

\section{HAL Id: hal-00803922 \\ https://hal.science/hal-00803922}

Submitted on 19 Mar 2021

HAL is a multi-disciplinary open access archive for the deposit and dissemination of scientific research documents, whether they are published or not. The documents may come from teaching and research institutions in France or abroad, or from public or private research centers.
L'archive ouverte pluridisciplinaire HAL, est destinée au dépôt et à la diffusion de documents scientifiques de niveau recherche, publiés ou non, émanant des établissements d'enseignement et de recherche français ou étrangers, des laboratoires publics ou privés.

\section{(c)(1)}

Distributed under a Creative Commons Attribution| 4.0 International License 
The torsion-tensile testing method for the characterization of cold metal formability

J. F. Fontaine Laboratoire de Mécanique des Composites et Collages, Université de Dijon , 6 Bd Gabriel , 21000 Dijon , France.

\begin{abstract}
Alstract
In cold forming, the materials are subject to very large stresses, the cold formability is in that case an essential property. This can be characteried by the measure of the striction after a tensile test following a torsion test. A theorical study of torsion-tensile testing, in large strain for elastoplastic behaviour with isotropic hardening is given. The problem is solved with the finite difference method, and a damage criterion is introduced for to expect the failure. A software has been made for to simulate the material behaviour in this test.
\end{abstract}

\title{
1. INTRODUCTION
}

Now, modern cold forming techniques play a more and more important role in the production of mechanical pieces, and the last possess excellent geometric characteristics as far as both dimensions and surface finish are concerned. This allows production time material losses and costs to be reduced.

The metal cold formability is so an essentiel quality, althoug, it's difficult to characterize because it depends in many factors. Different tests are usually used [1],[2]; among which torsion testing that can to obtain strains of the same order of size as thoses observed during cold forming processes [3]; the striction is generaly the parameter used for characterizing the ductillity. Our aim is to study the formability test introduced in [4]; it consists in carrying out torsion testing followed by tensile testing . Our objective is to explain the striction curves obtained after torsion- tensile testing, and to elaborate a computer program that predicts these curves .

\section{DESCRIPIION OF THE TEST}

The principle is the following: different cylindrical test pieces of $50 \mathrm{~mm}$ length and $3 \mathrm{~mm}$ radius ( $\mathrm{Ro}_{0}$ ) are twisted off with strain rates growing up to the failure; then they are subject to tensile testing up to failure. The diameter of the broken section is mesured and enables striction calculation.

$\mathrm{Z} \%=\left(1-\frac{\mathrm{S}}{\mathrm{S}_{1}}\right) \times 100$

where $S_{1}$ is the section before tensile testing and $S$ the broken section 
Then we can draw a curve $\mathrm{Z}=\mathrm{f}(\mathrm{N})$ where $\mathrm{N}$ represents the number of prestrain rotation wich depends of the useful length and of the diameter of the specimen. These curves make up an finished surface that permits a classification of materials the greater surface area, the more easily will materials be deformed.

\section{MODEIUNGS OF THE TEST}

\section{1. elastoplastic torsion testing}

\subsubsection{Kinematic aspects}

During torsion testing in large strain, we can note a lead effect according to the axis of the test piece; this phenomena is calling "Poynting effect" [5],[6].

Taking this observation into account, we choose a displacement field answering two hypothesis :

1. the strain is homogeneous according to the specimen axis

2. a straight section stays straight.

The field introduced by Murnagham [7] corresponds with these hypothesis:

$\mathrm{r}=\mathrm{r}_{0}+\mathrm{u}\left(\mathrm{r}_{0}, \Phi(\mathrm{t})\right) \quad$ where $\Phi(\mathrm{t})$ is the rotation by lenght unity

$\theta=\theta_{0}+\Phi(\mathrm{t}) . \mathrm{z}_{0} \quad\left(\mathrm{r}_{0}, \theta_{0}, \mathrm{z}_{0}\right)$ are the coordinates at the time $\mathrm{t}_{0}$

$\mathrm{z}=\mathrm{z}_{0}+\mathrm{w}(\Phi(\mathrm{t})) \mathrm{z}_{0} \quad(\mathrm{r}, \theta, \mathrm{z})$ are the coordinates at the time $\mathrm{t}$

Then we can write the strain rate tensor expressed on the actual configuration:

$$
\mathbf{D}=\left|\begin{array}{ccc}
\frac{\mathrm{u}, \mathrm{ro}, \mathrm{t}}{1+\mathrm{u}, \mathrm{ro}} & 0 & 0 \\
0 & \frac{\mathrm{u}, \mathrm{t}}{\mathrm{r}_{0}+\mathrm{u}} & \frac{1}{2} \frac{\mathrm{r}_{0}+\mathrm{u}}{1+\mathrm{w}} \Phi_{, \mathrm{t}} \\
0 & \frac{1}{2} \frac{\mathrm{r}_{0}+\mathrm{u}}{1+\mathrm{w}} \Phi_{, \mathrm{t}} & \frac{\mathrm{w}, \mathrm{t}}{1+\mathrm{w}}
\end{array}\right|
$$

and the spin tensor:

$$
\Omega=\left|\begin{array}{ccc}
0 & -\mathrm{zo} . \Phi, \mathrm{t} & 0 \\
\mathrm{zo} . \Phi_{, \mathrm{t}} & 0 & \frac{1}{2} \frac{\mathrm{r}_{0}+\mathrm{u}}{1+\mathrm{w}} \Phi_{, \mathrm{t}} \\
0 & -\frac{1}{2} \frac{\mathrm{r}_{0}+\mathrm{u}}{1+\mathrm{w}} \Phi_{, \mathrm{t}} & 0
\end{array}\right|
$$

\subsection{2. constitutive laws}

We are introducing here an elastoplastic behaviour in making the hypothesis of the strain partition:

$\mathbf{D}=\mathbf{D}_{\mathbf{e}}+\mathbf{D}_{\mathbf{p}}$ 
We choose a hypoelastic behaviour with the isotropic Hooke law:

$D_{e}=\frac{1+v}{E} D_{J} \sigma-\frac{v}{E} \operatorname{tr}\left(D_{J} \sigma\right) 1$

where $\sigma$ is the Cauchy stress tensor and $D_{J}$ the Jaumann derivative operator

and an incompressible plastic behaviour with the Prandlt-Reuss equation and the Von Mises criterion:

$\mathbf{D}_{\mathrm{p}}=\lambda \mathbf{s}=\frac{3}{2} \cdot \mathbf{g}^{\prime}(\bar{\sigma}) \frac{\mathrm{d} \bar{\sigma}}{\bar{\sigma}} \mathbf{s} \quad$ where $\mathbf{s}$ is the stress deviator

$$
\bar{\sigma}=\sqrt{\frac{3}{2} s_{i j} \cdot s_{i j}} \text { is the Von Mises equivalent stress }
$$

we use a law of the type: $\bar{\varepsilon}_{\mathrm{p}}=\mathrm{g}(\bar{\sigma})=\frac{\left(\bar{\sigma}-\sigma_{\mathrm{e}}\right)^{1 / \mathrm{n}}}{\mathrm{K} 1 / \mathrm{n}}$

$\mathrm{t}$

where

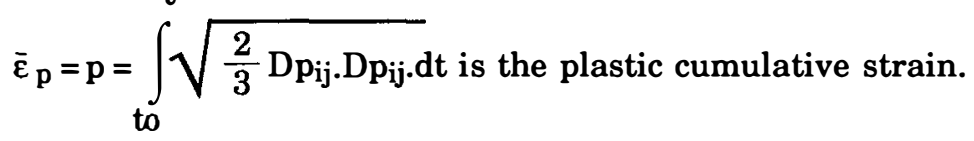

$\sigma_{\mathrm{e}}, \mathrm{K}$ and $\mathrm{n}$ are material constants

The calculations and the experiments are made for two different steels whose characteristics are summed up in the following table:

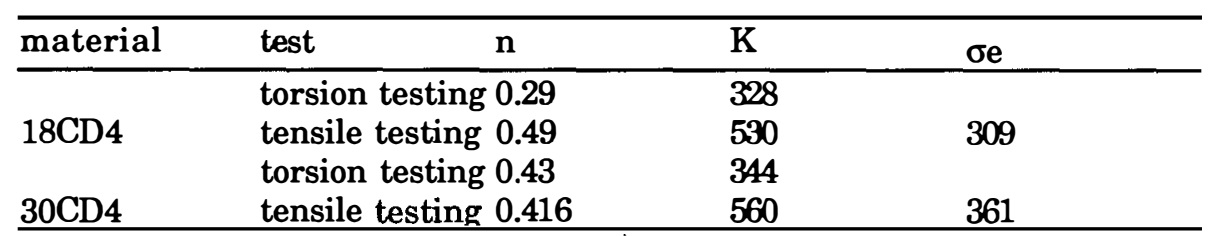

and the incompressibility condition is :

$$
\frac{u, r o, t}{1+u, r o}+\frac{u, t}{r_{0}+u}+\frac{w, t}{1+w}=\frac{3(1+2 v)}{E} \sigma_{H}
$$

where $\sigma_{H}=\frac{1}{3} \operatorname{tr}(\sigma)$ represents the hydrostatic pression

\subsection{3. equilibrium and boundary conditions}

Taking into account the provement field choosen, the static equilibrium $\operatorname{div} \sigma=0$ is reduced to only one equation:

$\sigma_{r r, r}+\frac{\sigma_{r r}-\sigma_{\theta \theta}}{r}=0$ or after calculation $\quad \sigma_{H}=\int_{r}^{R} \frac{s_{r r}+S_{z z}}{r} d r . s_{r r}$ 
The boundary conditions are the following:

- on the cylindrical surface:

- on the specimen extremities: $F_{z}=2 \pi \int_{0}^{R} \sigma_{z z}\left(r_{0}+u\right)\left(1+u, r_{0}\right) d r_{0}=0$

$$
C_{z}=2 \pi \int_{0}^{R} \sigma_{\theta z}\left(r_{0}+u\right)^{2}\left(1+u, r_{0}\right) d r_{0}
$$

\subsection{4. résolution}

The system of equations, ( 5 - 11) whose unknow are $s_{r r}, s_{z z}, s_{\theta z}, \sigma_{H}, u, w$ and $\mathrm{C}_{\mathrm{z}}$, is solved by an incremental computation with the finite differences method.

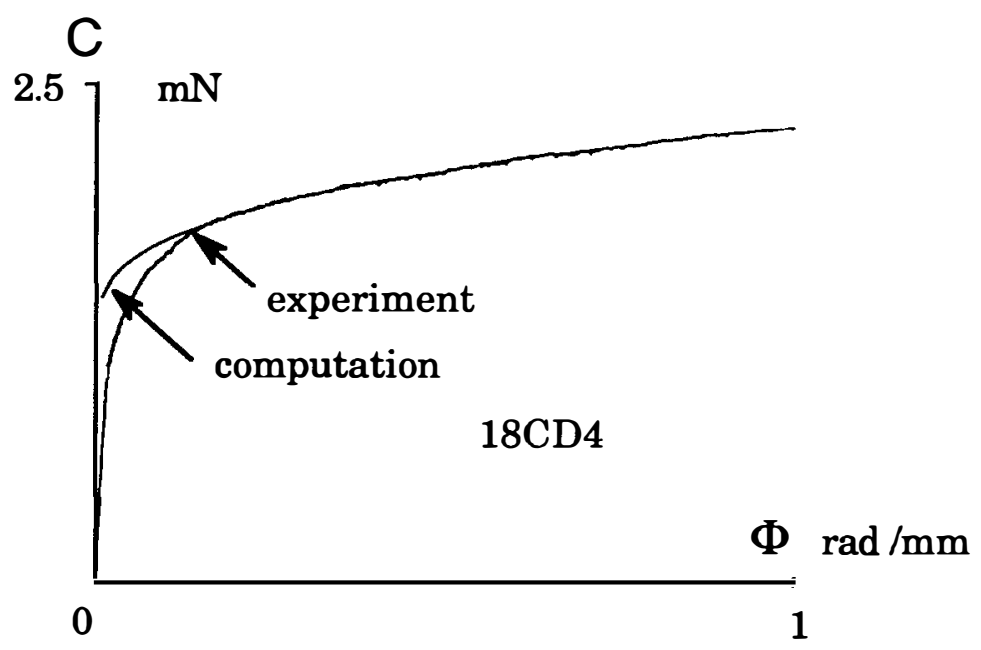

Figure 1. identification of the hardening from the torque and the rotation by unit of length

The result of the calculation shows that the strains induced on the axis remain small $\left(\varepsilon_{\mathrm{zz}}<0,5 \%\right)$ compared with the tangential strains $\left(\varepsilon_{\theta \mathrm{z}}=150 \%\right)$ likewise the normal stresses do not exceed 7.5 MPa for tangential stresses of $450 \mathrm{MPa}$.

\section{2 .tensile testing}

The tensile testing is solved from the same basic equations (5-11), the boundary conditions changing $\left(\mathrm{C}_{z}=0\right.$ and $\mathrm{F}_{\mathrm{z}}$ unknowed), as is the elastic boundary that depend on the radius. We can also remark the presence of residual stress after elastic slackness in torsion testing.

The following figures shows the evolution of the axial stress computed at the moment of the failure for different prestrain rates in torsion testing, the other stresses remain negligible. 


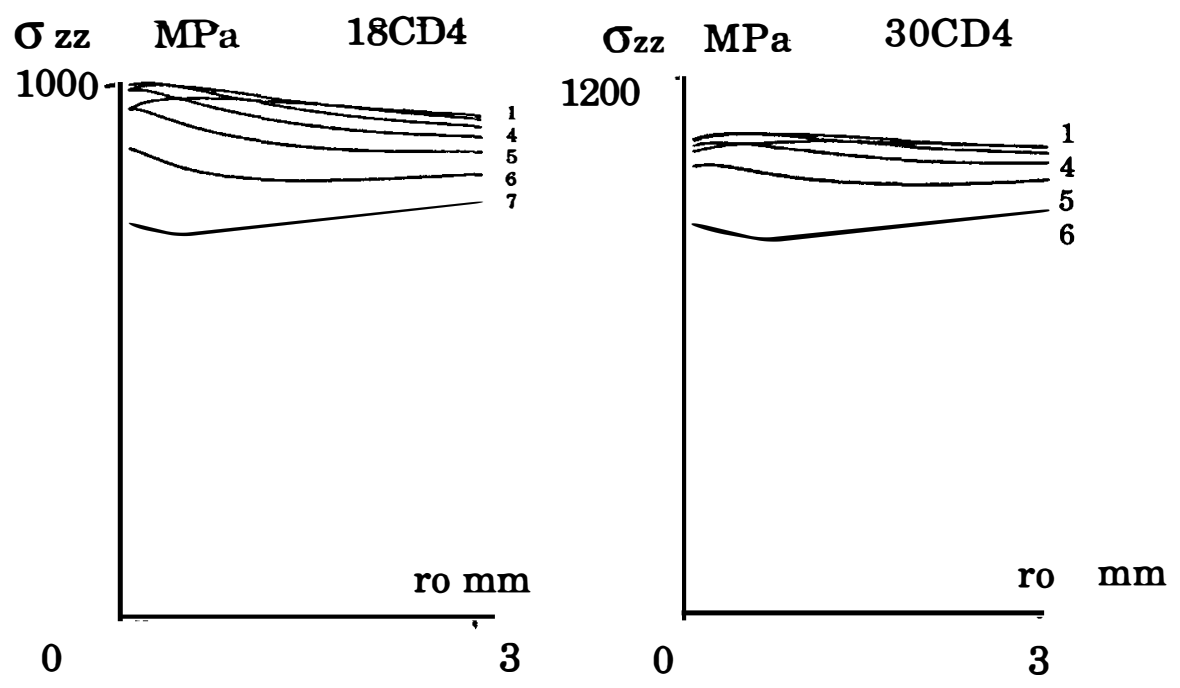

Figures $2 \mathrm{a}$ and $2 \mathrm{~b}$. axial stresses in tensile testing at the failure after different rotations in torsion testing for the both metals.

On the next figure, we can note the good correspondance between the averaged axial stress measured and computed in tensile testing after torsion testing.

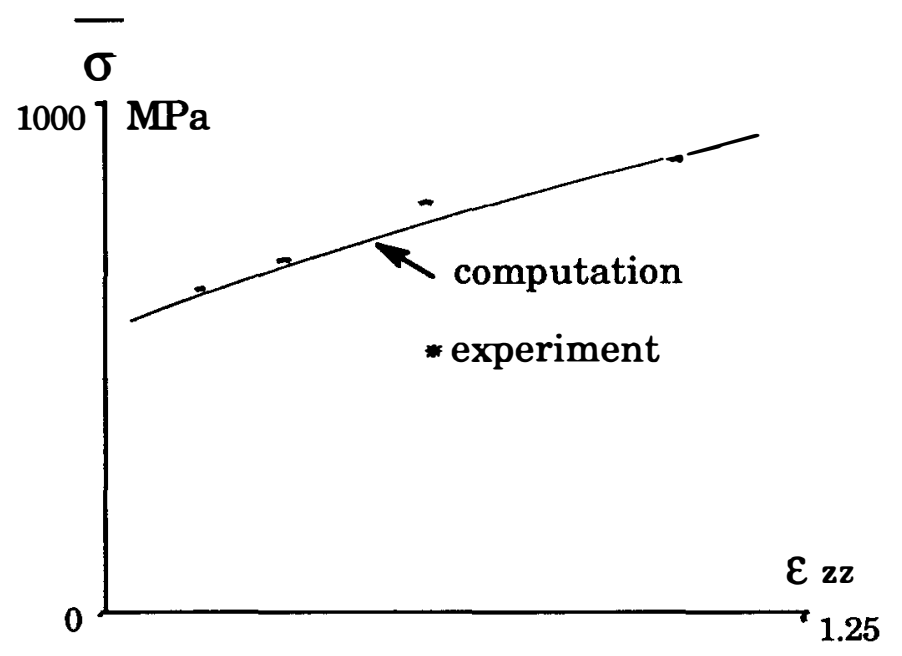

Figure 3. comparison between the averaged axial stress measured and computed in tensile testing after 3 rotations in torsion testing. 


\section{FAILURE CRITERION}

We use three criterions that we are comparing:

* isotropic plastic ductil damage [9]

We introduce the isotropic plastic ductil damage variable $D$ so as $D=0$ characterizes the blank material and $\mathrm{D}=\mathrm{Dc}$ gives the starting of a macro-crack:

$D, t=\frac{\sigma^{*}, t}{S} \cdot\left(\frac{\sigma^{*}-\sigma_{D}}{S(1-D)}\right) S \quad$ if $\sigma^{*}, t>0$ and $\sigma^{*}=\sup \left(\sigma_{D}, \sigma^{*}\right)$

$D, t=0 \quad$ if $\sigma^{*}, t<0$ or if $\sigma^{*}, t>0$ and $\sigma^{*}<\sup \left(\sigma_{D}, \sigma^{*}\right)$

where $\sigma^{*}=\sqrt{\frac{2}{3}(1+v) s_{I I}+3(1-2 v) \sigma_{H}}$ is the equivalent stress.

$\sigma_{\mathrm{D}}, \mathrm{s}$ and $\mathrm{S}$ are material constants given by the following table

\begin{tabular}{lccccc}
\hline material & test & DC & $\sigma_{\mathrm{D}}$ & $\mathrm{S}$ & $\mathrm{s}$ \\
\hline & traction & 0.42 & 309 & 690 & 0.79 \\
$18 \mathrm{CD} 4$ & torsion & 0.402 & 348 & 363 & 1.55 \\
& traction & 0.39 & 361 & 701 & 1.04 \\
$30 \mathrm{CD} 4$ & torsion & 0.41 & 426 & 426 & 0.99 \\
\hline
\end{tabular}

We make the hypothesis that the damage is cumulative .

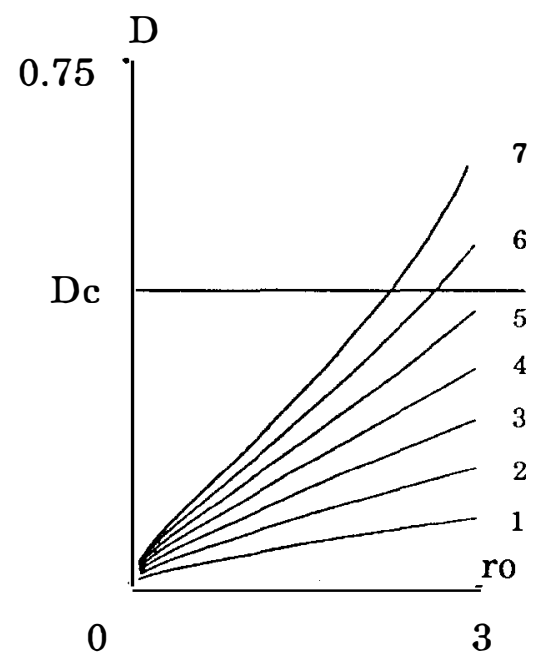

Fig 4. radial distibution of the computed damage for $18 \mathrm{CD} 4$

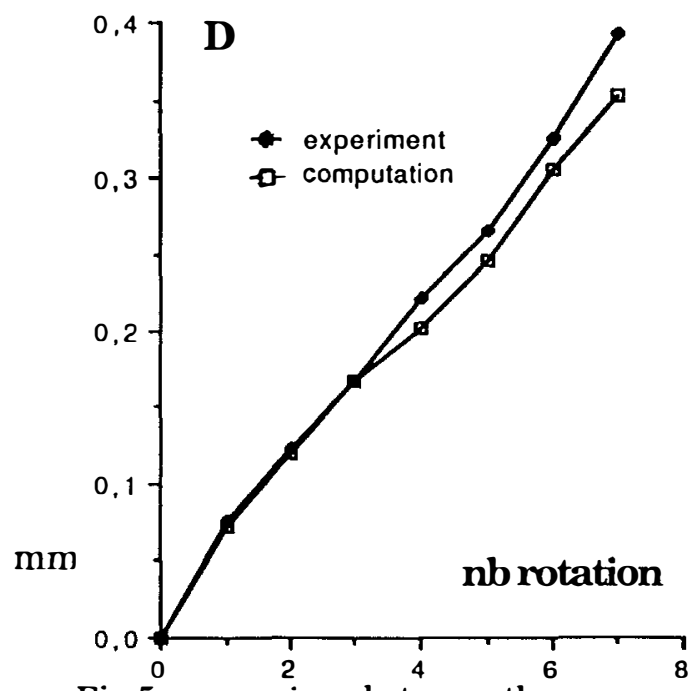

Fig 5. comparison between the averaged computed and measured damage 
We can note on the figure 4. that, in torsion testing, the damage at the specimen periphery is greater than the failure damage Dc. The figure 5 shows the good agreement between the averaged calculated and measured damage for 18CD4.

On the figures $6 a$ and $6 \mathrm{~b}$ representating the radial repartition of the damage at the failure in tensile testing, we can observe for weak strains that the maximun damage is situated near the axis of the test piece, on the other hand, for large strains the maximum damage is situated on the periphery.

$\mathrm{D}$

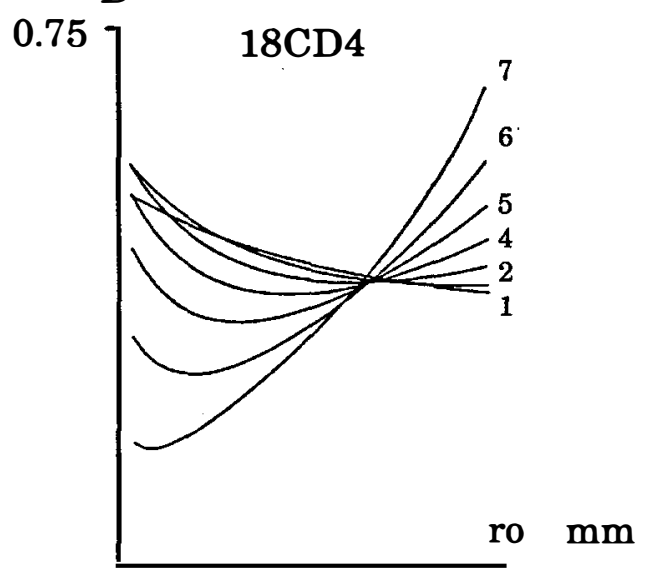

Figure 6 . radial repartition of 3

Figure 6 . radial repartition of damage at failure in tensile testing for different torsion prestrains

* energetic criterion [10]

introduced by Latham and Cokcroft :

$$
C=\int_{0}^{\bar{\varepsilon}_{r}} \frac{\sigma_{1}}{\bar{\sigma}} \bar{\sigma} d \bar{\varepsilon}
$$

where $C$ material constant

$\varepsilon_{\mathrm{r}}$ equivalent strain at failure

$\sigma_{1}$ the maximum tensile stress

* plastic strain criterion:

We calculate the plastic strain at the failure: $P_{R}=\frac{\varepsilon_{r}}{\left(\frac{2}{3}(1+v)+3(1+2 v)\right) \frac{\sigma_{H}}{\sigma}}$

$P_{R}$ is averadged on the specimen section : $P_{R}=\frac{2}{R^{2}} \int_{0}^{R_{1}} P_{R}\left(r_{1}+u\right)\left(1+u, r_{1}\right) d r_{1}$ 


\section{DETERMINATION OF THE CURVES $Z=f(N)$.}

The next figures show that the curve obtained with the damage criterion corresponds well with the experimental curve, where we can observed a great decreasing of the residual striction from a certain torsion prestrain.
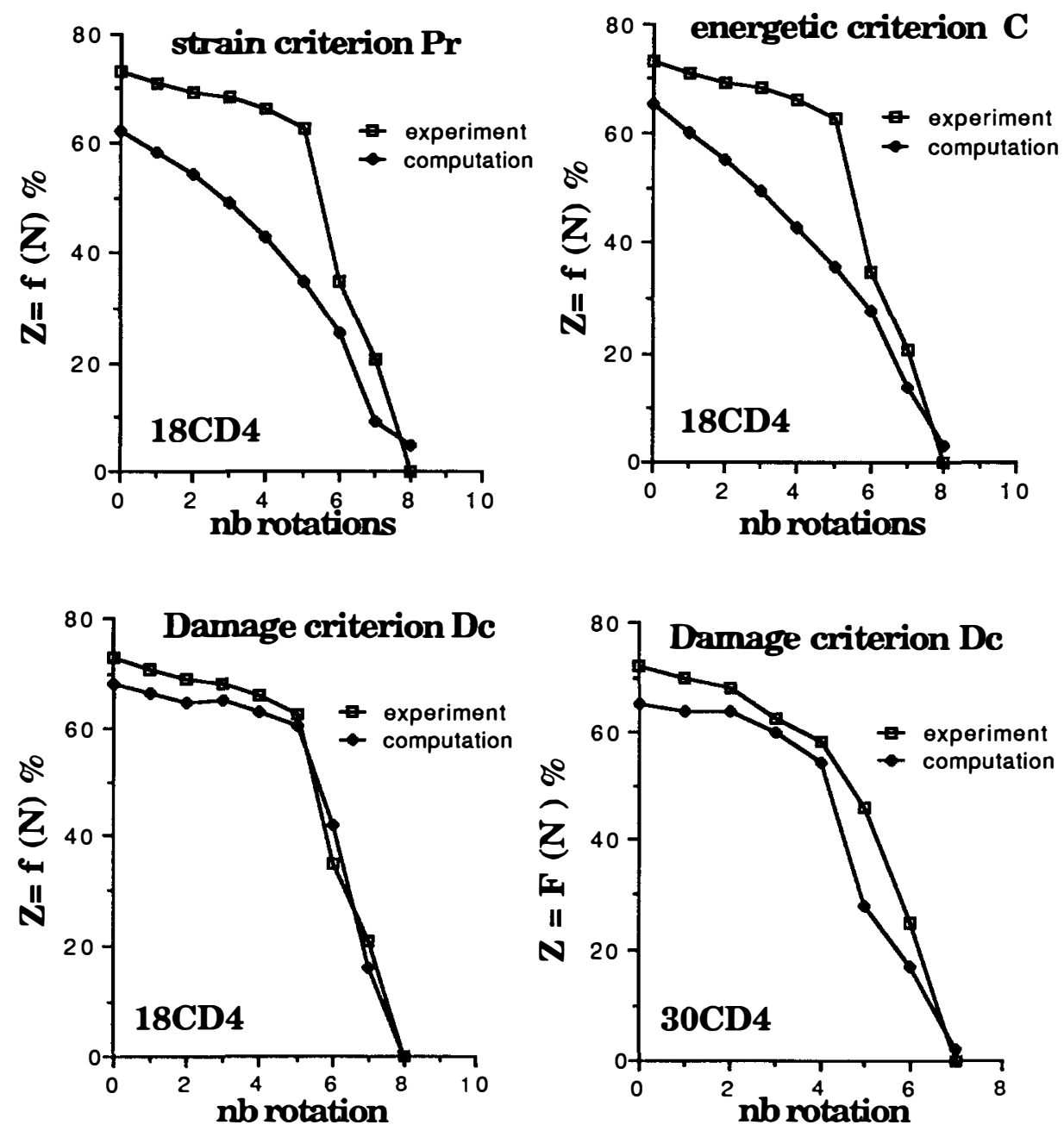

Fig 7 a-b-c-d comparison of residual striction for different failure criterions 


\section{COMPARISON TORSION+TENSILE TESTING AND EXIRUSION +TENSILE TFSTING}

We have realised extrusion experiments with the both materials, for different reduction rates about $20 \%, 40 \%, 60 \%$,and after we have made tensile testing on a specimen axialy extracted of the extruded piece.

The next figure indicates the residual striction after torsion or extrusion.

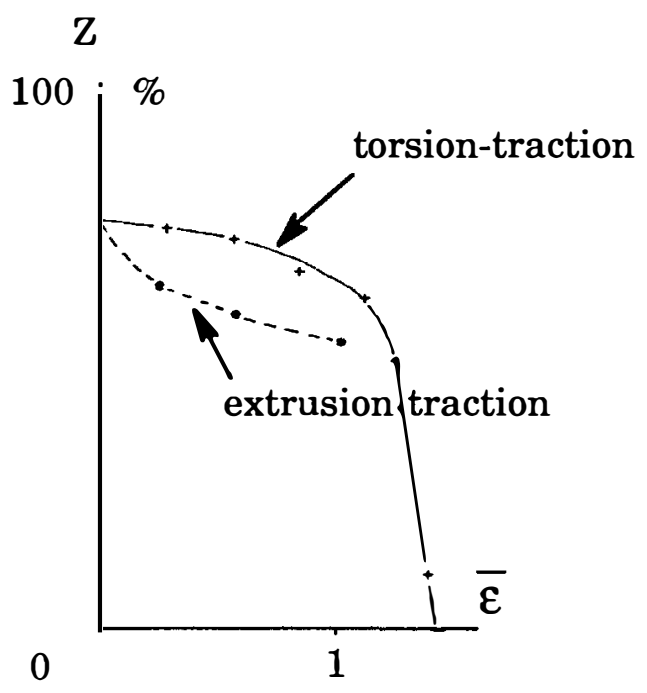

Figure 8. comparison between the striction obtained after extrusion+tensile testing and torsion + tensile testing

We remark that both curves have the same configuration,in their first parts. We do not have points on the second part that corresponds to extrusion reduction rates above $65 \%$.

\section{CONCLUSIONS}

Our work shows that using a failure criterion based on the ductil damage, we can definite the residual striction curves after torsion testing. The brutal fall of ductility from a certain strain in torsion testing can be explained by the fact that the material damage exceed the critic averaged damage at the specimen periphery. The curve obtained for different torsion rates is comparable to the curve obtained for extrusion specimens. So the torsiontensile testing is a good test for to determine the metal formability

The numerical schema suggested permits restricting the experiment to one test in simple torsion testing and one other in simple tensile testing for to determine the material characteristics 


\section{REFERENCES}

1 G.R. Canova and all, The use of torsion testing to assess material formability , Formability of metallic materials, ASTM STP 753, American Society for Testing and Materials, 1982, pp189-210

2 J.C. Gélin, J. Oudin, Y. Ravalard,Influence de quelques paramËtres métallurgiques sur la rupture ductile des acier. Mémoire scientifiques Revue de métallurgie, pp 169-179, avril 1984.

$3 \mathrm{~J}$. Pospiech , An investigation into the possibility of the determination of boundary strain from on mechanical test, Jour. of Mech. Working Tech., Vol 10, pp 325-347, 1984

4 L. Ackermann, M. Hugo, J. Bellot, Contribution, la recherche d'un critËre d'aptitude de formage, froid des aciers, Mémoire scientifiques Revue de métallurgie, pp 461-473, juin 1975.

5 E.W. Billington, Non-linear mechanical response of various metals. J. Phys. D: Appl. Phys., Vol 9, 1976, pp 533-552 , 1976.

6 B. Wack, Second and third-order effects in the torsion of circular tubes and rods, Journal de Mécanique, Vol 20, $\mathrm{N}^{\circ}$ 4,pp 737-787, 1981.

7 F. D. Murnaghan, Finite Deformation of elastic solid, John Wiley and Sons, New York, 1951.

8 D. S. Fields, J. and W. A. Backofen, determination of strain-hardening, characteristics by torsion testing , Proc. American , Soc. Test. Nat. Vol 57, pp 1259-1272

9 J. Lemaitre, Damage modelling for prediction of plastic or creep fatigue failure in structures, 5ty conference on structural mechanics in reactor technology, S.M.I.R.T. 5 , Berlin August 1979

10 M. G. Cockcroft and D. J. Latham, Ductility and workability of metals, Journal of the institute of metals, 1968, Vol 96, pp 33-39 